COMMENT. These authors and associates recently described an increased prevalence of growth-hormone deficiency in patients with Sturge-Weber syndrome, 18-fold higher than in the general population (Miller RS et al. Arch Dis Child 2006;91:340-341). On the basis of their current report of central hypothyroidism in $2.4 \%$ of cases, they recommend routine thyroid-function studies in patients with Sturge-Weber syndrome.

Russell and Rubinstein, in their Pathology of Tumors of the Nervous System (London, Arnold, 1959:72-92) classify cerebral vascular malformations in four groups: arteriovenous malformations, cavernous malformations, capillary telangiectases, and venous malformations. Sturge-Weber leptomeningeal angiomatosis (capillary angioma; telangiectasia) is mainly admixed with a venous malformation; cortical calcifications are found beneath the vascular malformation or localized to cortical tissue around the walls of smaller blood vessels (Wohlwill FJ, Yakovlev PI. Histopathology of meningo-facial angiomatosis (Sturge-Weber disease). J Neuropathol Exp Neurol 1957;16:341).

Cavernous angiomas, typically located in the cerebral hemispheres, involving the Rolandic region, are uncommon in childhood but are responsible for $12 \%$ of intracranial hemorrhages due to vascular malformations (Menkes JH. Textbook of Child Neurology. Philadelphia, Lea \& Febiger, $3^{\text {rd }}$ ed. 1980;598-607). The definition of cerebral cavernous malformations (CCM) is discussed in light of histopathological findings in 87 patients treated surgically at the Medical University of Vienna, Austria (Frischer JM, et al. J Neurol Neurosurg Psychiatry July 2008;79:783-788). CCM is currently defined as a mulberry-like assembly of thin walled vascular sinusoids lined by a thin endothelium, with no intervening brain parenchyma, and surrounded by hemosiderin deposits and gliosis. These authors found intervening brain parenchyma between vessels in $70 \%$ of otherwise typical specimens, and they suggest a modification of the definition of CCM.

\title{
BRAIN TUMORS AND MALFORMATIONS
}

\section{LONG-TERM OUTCOME OF INFANTILE BRAIN TUMORS}

Twenty seven consecutive patients diagnosed with brain tumor in the first year of life, between 1980 and 2005, were followed at the University Children's Hospital of Zurich, Switzerland. Of 11 survivors at mean follow-up of 12.3 years, 9 had persistent neurological complications, 4 had endocrine and growth complications, and 8 had cognitive deficits with school problems and poor occupation choices. Behavioral and psychological problems occurred in 7 patients, and health-related quality of life, especially social functioning, was generally impaired. Patients with high-grade tumor histology and intense therapy had the lowest quality of life. (Gerber NU, Zehnder D, Zuzak TJ, Poretti A, Boltshauser E, Grotzer MA. Outcome in children with brain tumors diagnosed in the first year of life: long-term complications and quality of life. Arch Dis Child July 2008;93:582-589). (Respond: Dr Michael A Grotzer, University Children's Hospital, Steinweisstrasse 75, CH-8032 Zurich, Switzerland. E-mail: michael.grotzer(akispi.uzh.ch).

COMMENT. With long-term survival, the importance of quality of life issues is increased and requires early intervention. Children with brain tumors requiring treatment with radiotherapy are particularly prone to cognitive, behavioral and social problems. 